\title{
Tierra y derechos humanos en Chile: la contrarreforma agraria de la dictadura de Pinochet y las políticas de reparación campesina
}

\author{
JoAna SAlÉM Vasconcelos
}

PALABRAS CLAVE: contrarreforma agraria, Chile, dictadura, derechos humanos.

CÓDIGOS JEL: N56, Q15, J15, K38.
7 a reforma agraria chilena, ocurrida entre 1967 y 1973, representó un proceso masivo de distribución de nueve millones de hectáreas de tierras a campesinos bajo condiciones democráticas y dentro de la ley. Sin embargo, la dictadura inaugurada con el golpe de Estado del 11 de septiembre de 1973 emprendió un proceso de contrarreforma agraria, devolviendo parte de los asentamientos a los antiguos due- ños, fragmentando otra parte en parcelas, transfiriendo y adjudicando otros sectores en subastas.

Este trabajo presenta una sintesis de los estudios sobre la contrarreforma agraria en Chile desde la perspectiva de los derechos humanos, con objetivo de articular cuestión agraria y justicia de transición. Con base en documentos primarios, se argumenta que el proyecto represivo y el proyecto económico agrícola de la dictadura de Pinochet estaban integrados a una misma agenda de violaciones. La reparación campesina en democracia fue insuficiente, pues no logró restituir el derecho humano más importante: la propiedad de la tierra para las familias victimadas por la dictadura. 


\section{Land and human rights in Chile: agrarian counter-reform under the Pinochet dictatorship and peasant reparation policies}

\section{KEYWORDS: agrarian counter-reform, Chile, dictatorship, human rights.}

\section{JEL CODES: N56, Q15, J15, K38.}

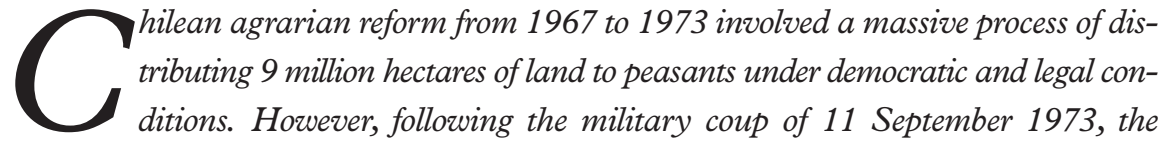
Pinochet dictatorship initiated agrarian counter-reform, which involved returning some of the settlements (asentamientos) to their former owners, fragmenting others into plots and transferring or selling other sections. This paper presents a synthesis of the research on agrarian counter-reform in Chile from the perspective of human rights, with the aim of articulating the agrarian question and transitional justice. It draws from primary sources to argue that the repressive and agrarian economic projects of the dictatorship corresponded to the same agenda of violation. Peasant compensation under democracy was insufficient and failed to restore the most important human right: land property to families victimized by the dictatorship.

Joana Salém Vasconcelos [https://orcid.org/0000-0002-2984-7630] es doctoranda en Historia Económica en la Universidad de São Paulo (USP), fue visiting researcher en la Universidad de California, Irvine (UCI). Es investigadora del Centro de Estudios de Historia Agraria de América Latina (CEHAL), en la Universidad de Santiago de Chile (USACH).C.e.:joana.salem@gmail.com 
[...] los campesinos chilenos están sufriendo de desnutrición, con graves problemas habitacionales y en un mercado fríamente competitivo, son incapaces de enfrentar las trabas que el sistema económico les impone [...] sufren toda clase de arbitrariedades. Nunca, como en el presente, se encuentran más indefensos ante autoridades o empresarios, pues dificilmente cuentan con asistencia jurídica oportuna y desinteresada ${ }^{1}$.

Profanaron lo más intimo nuestro La paz de nuestros hijos y mujeres,

Ustedes rieron a carcajadas Cuando el hambre nos cundía ${ }^{2}$.

El desconocimiento y atropello por el Estado del derecho a la tierra destinada a esos campesinos constituyó claramente una violación masiva a la garantía constitucional de la propiedad ${ }^{3}$.

\section{INTRODUCCIÓN}

Las investigaciones sobre la política agraria de la dictadura de Augusto Pinochet en Chile (1973-1990) producidas hasta el día de hoy lograron informar y explicar el proceso de reversión de la reforma agraria conducida por los gobiernos democráticos anteriores, de Eduardo Frei Montalva (1965-1970) y de Salvador Allende (1970-1973). Tal reversión fue conceptualizada con los términos modernización excluyente (Ortega, 1987), modernización forzada (Gómez \& Echeñique, 1987), contrarreforma agraria (Bengoa, 1983; Jarvis, 1985) o contrarreforma agraria parcial (Bellisario, 2007a), entre otros. El presente trabajo pretende analizar el problema de la contrarreforma agraria de la dictadura chilena como una cuestión pendiente en el campo de la justicia de transición, destacando los nexos existentes entre los cambios de la estructura de propiedades rurales y las violaciones de derechos humanos de la población campesina. En ese sentido, se plantea una comprensión más amplia de la reparación campesina, que considera la propiedad de la tierra como un derecho humano violado ${ }^{4}$.

1. Fundación de Documentación y Archivo Vicaría de la Solidaridad (FDAVS), Memorias, doc. 0002500. Vicaría de la Solidaridad, «Tercer año de labor», 1979a, pp. 51-52.

2. Fragmento de un poema campesino (BENGOA, 1983: 193).

3. Bulnes, Fuenzalida y Toledo (2003: 185).

4. La literatura sobre el concepto de justicia de transición señala que existen cinco ejes clave para 
La articulación entre la cuestión agraria y la justicia de transición que se propone en este trabajo se fundamenta en dos informes encajonados por el gobierno de Ricardo Lagos (2000-2004), producidos por expertos de la Universidad Arcis, que fueron contratados por el Ministerio de Agricultura en dos ocasiones, en 2000 y en 2003, para formular recomendaciones de política para la reparación campesina. Los informes mapearon las irregularidades cometidas por la dictadura relacionadas con la usurpación del derecho de propiedad, ejecutadas por mecanismos represivos o económicos que excluyeron a masivos sectores del campesinado de la tierra. Aunque sea oficialmente reconocida la violencia contra los campesinos durante la dictadura, es poco conocido el hecho de que tales informes existieron y que hubo cierta vez una intención gubernamental -luego abortadade conocer, mapear y reparar tales violaciones ${ }^{5}$.

Junto con demostrar la naturaleza y los métodos de exclusión, los informes encajonados proponían fundamentos para una política reparatoria al campesinado chileno, en el mismo contexto en que se inauguraban los trabajos de la Comisión Verdad Histórica y Nuevo Trato con los Pueblos Indígenas (2001) y la Comisión Nacional sobre Prisión Política y Tortura (2003). Sin embargo, el tema de los derechos campesinos no alcanzó la misma importancia pública. Quizá existiera una incipiente disponibilidad para articular la cuestión agraria y la justicia de transición cuando el ministro de Agricultura del gobierno de Lagos contrató los estudios y solicitó soluciones de reparación campesina. No obstante, a pesar de la claridad de sus recomendaciones, los informes fueron encajonados e ignorados, transformándose en letra muerta y olvidada ${ }^{6}$.

su cumplimiento: el restablecimiento de la verdad; la construcción de políticas de memoria; la efectuación de la justicia a los responsables por los crímenes de Estado; la garantía de reparación a las víctimas; y la aplicación de reformas institucionales que democraticen los organismos violadores de derechos. Dentro de esa comprensión, quisiéramos destacar las políticas de reparación, que son parte esencial para el éxito del proceso transitorio (MEZarobba, 2007; Collins, 2013; Rojas, 2016).

5. Llamaré informes encajonados a estos dos documentos nunca publicados, ambos contratados por el Ministerio de Agricultura. El primero, de 2000, fue llevado a cabo por un equipo de cinco abogados (José María Bulnes, Roberto F. Celedón, Matías R. Coll, Sergio B. Fuenzalida, Leonso G. González). El segundo, de 2003, expandió la metodología a nivel nacional y propuso recomendaciones de reparación a los campesinos, con autoría de José María Bulnes, Sergio B. Fuenzalida y Víctor Toledo Llancaqueo. En abril de 2017, el segundo informe me fue presentado por don Jacques Chonchol. Poco después, en junio de 2017, una fotocopia del primer informe me fue presentada por Juan Vergara. No existen indicios de que estos documentos estén disponibles en bibliotecas o archivos públicos. Dejo a ambos mis agradecimientos.

6. La repercusión de los informes encajonados fue insignificante y el mundo político no les hizo caso. Sobre el primer informe (2000) no encontramos ninguna publicación, con lo que aparenta ser casi desconocido del universo académico y sindical. Sobre el segundo (2003) existen al menos dos publicaciones: un artículo en la revista América Latina (Toledo, FuenZALIDA \& Bulnes, 2004) y un comentario de cuatro páginas en la página-web del Centro de Estudios Miguel Enríquez, de 2004, sin autoría determinada. 
Propongo, entonces, la articulación entre cuestión agraria y justicia de transición a través del entendimiento de la propiedad de la tierra como derecho humano. Con tal articulación, las violaciones contra campesinos durante la dictadura en Chile son redimensionadas si se considera la alianza entre el proyecto represivo y el proyecto económico agrícola del régimen, evidenciada en las fuentes documentales aquí analizadas. Hay evidencias de que el proyecto represivo que afectó al campesinado y el proyecto económico agrario de la dictadura formaron una estrategia única que condujo al mismo objetivo: expulsar a los campesinos de la tierra por vía del terrorismo de Estado, el endeudamiento y las presiones del mercado, herramientas integradas de la acumulación por desposesión (Harvey, 2004; Matheus e Silva, 2016). En ese contexto, planteamos que las demandas de los campesinos por la propiedad de la tierra podrían ser escuchadas desde la perspectiva de la reparación histórica.

El texto se organiza en las siguientes partes. Primero, presentaré las principales contribuciones de la bibliografía sobre la contrarreforma agraria en Chile y la fragilización de las organizaciones campesinas desde 1973. En segundo lugar, analizaré aspectos de las violaciones de derechos humanos campesinos durante la dictadura, con base en los informes del Departamento Campesino de la Vicaría de la Solidaridad y de las Comisiones de la Verdad de Chile ${ }^{7}$. Seguidamente, contaré la historia de los informes encajonados por el Gobierno chileno en 2000 y 2003, considerando la relevancia de las recomendaciones reparatorias no adoptadas. Y por fin, tejeré las consideraciones finales sobre la importancia de la articulación entre la tierra y los derechos humanos, buscando el entendimiento del derecho a la propiedad campesina como parte de la justicia de transición.

\section{LA CONTRARREFORMA AGRARIA DE LA DICTADURA DE PINOCHET}

Entre 1965 y 1970, el gobierno demócrata cristiano de Eduardo Frei Montalva había expropiado 3.563.554 hectáreas de riego básico (en adelante, HRB) -que afectaron a 1.408

7. El Estado de Chile produjo tres comisiones de la verdad en las últimas tres décadas: la Comisión Nacional de Verdad y Reconciliación en 1990 (presidida por el jurista Raúl Rettig) investigó los muertos y desaparecidos; la Comisión de la Verdad Historia y Nuevo Trato con los Pueblos Indígenas en 2001; y la Comisión Nacional sobre Prisión Política y Tortura, que en 2003-2004 oficializó los casos de detenidos y torturados (presidida por el monseñor Sergio Valech). La Comisión Valech fue reabierta en 2010-2011 y actualizó los reconocimientos. La cifra oficial de víctimas de la dictadura reconocida por el Estado chileno hoy día es de 3.216 desaparecidos/asesinados y 38.254 detenidos/torturados (GobIERNo DE ChILE, 1990, 2004, 2011). 
propiedades rurales de Chile-, para la formación de asentamientos de reforma agraria. El gobierno de la Unidad Popular, haciendo uso de la misma ley 16.640 (Gobierno de Chile, 1967b), llegó a expropiar 5.296.756 HRB pertenecientes a 3.282 propiedades rurales, entre noviembre de 1970 y el 11 de septiembre de 1973 (Barraclough \& Fernández, 1974: 75). Según los autores del Diagnóstico sobre la reforma agraria chilena, nunca un país había expropiado cantidad tan extensa de tierras fértiles dentro de un proceso legal e institucionalmente respaldado. Sin embargo, el sector reformado, que alcanzó el 35\% de la superficie agrícola del país antes del golpe de Estado, fue drásticamente fragmentado por la dictadura.

En los años 1980, chilenos del Grupo de Investigaciones Agrarias (GIA), del Centro de Estudios de la Mujer (CEM), del Grupo de Estudios Agro-Regionales (GEA) y de la FLACSO realizaron importantes labores en el sentido de conocer los actos de la dictadura frente a los campesinos y la tenencia de la tierra, además de recolectar narrativas de hombres y mujeres rurales sobre las transformaciones agrarias, en un sentido crítico a la modernización autoritaria. Gómez y Echeñique $(1986,1987)$ y Ortega (1987) demostraron los altos costos de la opresión social del modelo de modernización agraria adoptado por la dictadura, el crecimiento de la desigualdad rural, el fenómeno del desarraigo y la expansión del trabajo precario de los temporeros, especialmente mujeres. En el mismo sentido, Bengoa (1983) y Rivera y Cruz (1984) fueron sobre el terreno a documentar la situación crítica de las familias campesinas expulsadas de sus tierras en plena dictadura, viviendo en villorrios y poblaciones callampa en los márgenes de las rutas, experimentando niveles de pobreza antes desconocidos, decurrentes de la violación de su derecho a propiedad. Mientras tanto, Acuña (1986), Valdés, Mack y Matta (1986), y Valdés (1987) escucharon y editaron relatos de vida de mujeres campesinas, y aportaron nuevas interpretaciones sobre desigualdad de género y ruralidad.

Entre los primeros investigadores en sistematizar los cambios de la distribución de propiedades agrarias visibles en 1979, poco antes de la inauguración del libre mercado de tierras en 1980, estuvieron Cereceda y Dahse (1980), Bengoa (1983), Jarvis (1985), y Gómez y Echeñique (1987). Con la combinación de datos provenientes de distintos organismos gubernamentales ${ }^{8}$, supieron que durante los primeros años de dictadura la tenencia de la tierra se modificó aproximadamente como muestra la Tabla 1.

En seis años, el fenómeno del minifundio (menor de $5 \mathrm{HRB}$ ), asociado a la pobreza rural, se había más que duplicado en superficie. Mientras tanto, las parcelas pequeñas y

8. El Servicio de Impuestos Internos (SII), el Servicio Agrícola Ganadero (SAG), la Corporación de Reforma Agraria (CORA) y la Oficina de Planificación (ODEPA), entre otros. 
medias (de 5 a $20 \mathrm{HRB}$ ) crecieron, pues coincidían con los proyectos de parcelación individual de tierras conducidos por la dictadura y la pulverización del sector reformado. En contrapartida, el tramo de propiedades entre 20 y $80 \mathrm{HRB}$, que abrigaba asentamientos, CERA (Centro de Reforma Agraria), cooperativas, comités, fue reducido a menos de la mitad y homogeneizado en forma de propiedad privada convencional. Por fin, los latifundios (mayores de $80 \mathrm{HRB}$ ), casi eliminados por la Unidad Popular, resurgieron multiplicando por diez la superficie ocupada.

\section{TABLA 1}

\begin{tabular}{lrr}
\multicolumn{3}{c}{ Tenencia de la tierra en Chile (\%), $\mathbf{1 9 7 2}$ y $\mathbf{1 9 7 9}$} \\
\hline Propiedades & $\mathbf{1 9 7 2}$ & $\mathbf{1 9 7 9}$ \\
\hline Menores que 5 HRB & 9,7 & 23,2 \\
5 a 20 HRB & 13,0 & 27,7 \\
20 a 80 HRB & 38,9 & 15,6 \\
Mayores que 80 HRB & 2,9 & 29,8 \\
Sector reformado & 35,5 & 0 \\
\hline
\end{tabular}

Fuente: Jarvis (1985).

La dictadura devolvió el $28 \%$ del sector reformado a los antiguos propietarios y otro $20 \%$ $30 \%$ fue rematado a precios muy bajos, específicamente los predios en conflicto judicial o en pose de campesinos perseguidos por la represión (Cereceda \& Dahse, 1980: 106; Bengoa, 1983: 46). Estudios de Gómez, Arteaga y Cruz (1979) indicaron que aproximadamente la mitad de las solicitudes de parcelas hechas por los campesinos fueron rechazadas por la dictadura, lo que correspondía a 33.000 familias rurales excluidas del derecho a tierra por no alcanzar suficiente puntaje $^{9}$. Según se supo en los años 1980, los proyectos de parcelación de la dictadura distribuyeron entre el $26 \%$ y el $41 \%$ de las tierras reformadas en unidades agrícolas familiares (UAF), entregadas para $36.553 \mathrm{cam}-$ pesinos ideológicamente seleccionados en función del decreto 208. El decreto proscribía la asignación de tierra a quien fuera condenado o encargado reo por sentencia ejecutoriada por delito que merezca una pena de presidio mayor en cualquiera de sus grados y a quienes hubieren ocupado con violencia el predio objeto de la destinación (Gobierno de Chile, 1973). Considerando que la dictadura transformó en reo a todo ciudadano que resistiera a sus prácticas, al criminalizar la participación política per se, y además que mi-

9. Los criterios de selección de parceleros por sistema de puntaje fueron alterados por la dictadura. Los principales cambios fueron: a) las personas no asentadas fueron incluidas en proyectos de parcelación; b) el aumento del puntaje por años de servicio administrativo favoreció a los funcionarios de la burocracia; y c) se acrecentó una evaluación del antiguo dueño del fundo sobre el campesino, o sea, el patrón opinaba sobre los candidatos, muchos de ellos sus exsubordinados (BELLISARIO, 2007b: 157-163). 
llares de campesinos participaron de huelgas o tomas de fundo entre 1965 y 1973, el decreto 208 excluyó masivamente del derecho a la tierra a los campesinos más organizados y participativos de la reforma agraria.

Si por un lado la dictadura distribuyó del $26 \%$ al $41 \%$ de las tierras expropiadas en parcelas campesinas ${ }^{10} \mathrm{y}$, por lo tanto, pareciera cumplir parcialmente con un objetivo de la reforma agraria, cuando se abrieron las compuertas al libre mercado de tierras (decreto 3.262 de 1980), tales parcelas encontraron escasas posibilidades de sustentación. Por eso, Echeñique y Rolando (1991) fueron a entrevistar a parceleros y procurarlos. Correlacionando datos de estudios locales ${ }^{11}$, los autores estimaron que, en 1990 , ya se había vendido el $57 \%$ de las parcelas asignadas en la dictadura, generalmente a precios devaluados, lo que correspondía a 21.000 familias campesinas y el 10\% de las tierras del país (Echeñique \& Rolando, 1991: 16).

Los autores investigaron las razones de las ventas. Encontraron que la principal causa fueron las deudas originadas de la compra de la parcela (26\%), pues contrariamente a los gobiernos anteriores, la dictadura no ofreció condiciones viables de crédito a los campesinos y el propio régimen los endeudó con proyectos de parcelación. Fueron registradas ventas por falta de capital, mano de obra o apoyo técnico (21\%), por vejez y ausencia de trabajo familiar (10\%) y también por campesinos - muchos de ellos analfabetos-, que fueron engañados con contratos de arriendo que imponían la venta futura u otras estafas (6\%). Es lamentable comprobar aun ahora, escribieron los autores, la existencia de situaciones dramáticas de algunos familiares que viven su miseria a la orilla de caminos vecinos a las que fueron sus parcelas y sitios, perdidas por engaños de compradores deshonestos y contra cuyas argucias no tuvieron capacidad de defensa (Echeñique \& Rolando, 1991: 26).

Otros estudios fundamentales sobre la política agraria de la dictadura chilena fueron compilados por Kay y Silva (1992). En especial, es relevante el tema de la fragilización sindical campesina. Silva atestó que las divisiones internas del sindicalismo campesino se profundizaron aún más luego del golpe de Estado, pues las organizaciones vinculadas a la Democracia Cristiana apoyaron la dictadura hasta $1976^{12}$. Cuando la dictadura ex-

10. Cereceda y Dahse (1980) registran el $41 \%$; Bengoa (1983), el 26\%.

11. Echeñique y Rolando mencionan estudios parciales de Gómez, ICIRA, ICECOOP, INPROA, FUNDEB, INDAP, Cereceda y Dahse.

12. Las confederaciones Triunfo Campesino y Libertad se unieron a la Federación Sargento Candelaria para formar la Unión de Organizaciones Sindicales Campesinas, intento frustrado de interlocución junto al gobierno militar; mientras las confederaciones Ranquil y Unidad Obrero-Campesina, que apoyaban a la Unidad Popular y que en 1973 sumaban el 50\% de los cam- 
tinguió el Fondo de Educación y Extensión Sindical (FEES), vía DFL 1.446 de 1976, y luego cortó las líneas de crédito campesino del INDAP (Instituto de Desarrollo Agropecuario) y la CORA (Corporación de la Reforma Agraria), la Democracia Cristiana había recién pasado a la oposición ${ }^{13}$. Tales medidas, según Silva, inviabilizaron estructuralmente la organización sindical del campesinado, incluso el sector que demostró simpatía por el golpe de 1973.

\section{GRÁFICO 1}

Campesinos sindicalizados en Chile, 1965-2006

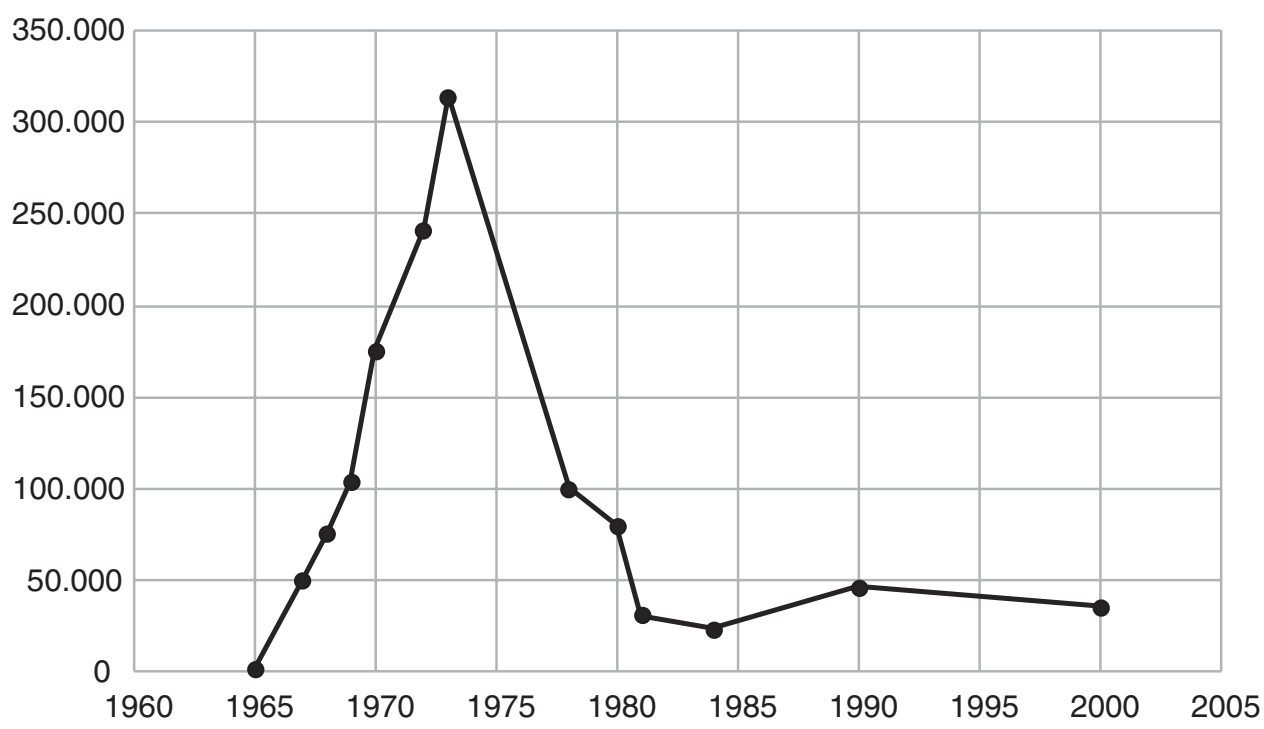

Nota: los números y fuentes consideradas para el gráfico son: en 1965, 1.500 campesinos sindicalizados; en 1967, 50.309 (Loveman, 1976: 131, 264-265); en 1968, 76.356; en 1969, 103.544; en 1970, 175.373; en 1972, 241.610 (Salinas, 1985 apud Tinsman, 2009: 313); en 1973, el auge de 313.700 (Barraclough \& Fernández, 1974: 179); en 1978, cerca de 100.000 (Gómez, 2002: 5); en 1980, 80.132 (Silva, 1992: 225); en 1981, 31.000 (Bengoa, 1983: 187-188); en 1984, 24.000 (FDAVS, doc. 0268100. Vicaría de la Solidaridad, «Noveno año de labor», 1984, p. 171); en 1990, 46.466; en 2000, 36.079 (Gómez, 2002: 5).

Fuente: elaboración propia.

Con el Plan Laboral de 1979, el poder de negociación sindical campesina fue destrozado. El paralelismo sindical facilitó la división campesina y las confederaciones perdieron oficialmente la facultad para negociaciones nacionales. El derecho de huelga, prohibido

pesinos sindicalizados en Chile, fueron proscritas y sus afiliados perseguidos y asesinados (SILVA, 1992: 221).

13. Creado por la ley 16.625 de sindicalización campesina (GOBIERNO DE CHILE, 1967a), entre 1967 y 1973 el FEES administró 7,6 millones de dólares y repasó 23 millones de dólares a organizaciones campesinas (GómEZ, 2002: 7). 
desde el golpe militar, fue repuesto, pero de manera tramposa. A los patrones de fundos les fue permitido contratar empleados para reemplazar huelguistas, que además sentían miedo por el contexto de terrorismo de Estado. Según los datos combinados de diferentes autores, el número de campesinos sindicalizados entre 1965 y 2000 evolucionó aproximadamente como muestra el Gráfico 1. Es interesante notar que hay dos olas de caída pronunciada de la afiliación sindical campesina: la primera (1973-1978) es resultado de la represión y la segunda (1980-1982) ocurre tan pronto se impone el Plan Laboral.

El inicio de la democracia generó relativo optimismo en sectores campesinos organizados. Gómez cuenta que, durante la campaña presidencial de 1990, los campesinos recompusieron sus demandas en una agenda mínima común. Exigían la reparación para aquellos campesinos que habian sido victimas de discriminación durante el proceso de reforma agraria, básicamente aquellos afectados por el DL 208 (Gómez, 2002: 13). Se solicitaba la distribución reparatoria de propiedades, por medio de la formación de un fondo de tierras con tierras fiscales y con reservas que se encontraban en poder del Estado (Gómez, 2002: 13; Observatorio de Derechos Humanos, 2012: 8). La demanda no fue atendida. El paradigma productivo de la especialización flexible, instaurado en la dictadura, hegemonizaba el lenguaje político con una perspectiva de aislar los grupos carentes de otros (Gómez, 2002: 13), generando políticas focalizadas para la pobreza en separado del desarrollo agrícola del país. La reforma agraria no volvió a la pauta. Mientras para la mayoría de los dirigentes campesinos, se trataba de una tarea pendiente que habia que retomar una vez conquistada la democracia, escribió Gómez, para muchos dirigentes y analistas, la reforma agraria era un tema del pasado (Ibid.: 12).

Como muestran los trabajos de Cristóbal Kay sobre la globalización de la agricultura chilena, las políticas agrarias desde la dictadura sufrieron pequeñas inflexiones, de un neoliberalismo dogmático (1973-1983), que destruyó la seguridad alimentaria, hacia un neoliberalismo pragmático (1983-1990), que siguió privilegiando los cultivos de exportación, pero ofreciendo algún grado de proteccionismo para cultivos básicos, anuales y tradicionales (Kay, 2002: 473). Kay se preguntaba: ¿en cuál extensión las políticas agrarias post-1989 se diferencian de los años de Pinochet? (Ibid.: 474). Con investigación, respondió: la política económica de la transición democrática puede ser caracterizada por perseguir una "continuidad con cambio", un "neoliberalismo con rostro humano» [...]. El neoliberalismo pragmático fue perpetuado, pero con mayor énfasis en la agricultura campesina $y$ las políticas sociales ${ }^{14}$ (Ibid.: 474). Según Kay, los gobiernos de la Concertación en los años 1990 respaldaron el modelo económico agrícola de la dictadura, priorizando las metas de crecimiento por exportación, las ventajas comparativas y la competencia en las ca-

14. Traducción de la autora. 
denas globales de valor. Como resultado, según los análisis de Valdés y Araujo (1999) y Tinsman (2016), el trabajo devaluado de las mujeres campesinas (temporeras) fue incorporado como ventaja comparativa en las exportaciones frutícolas.

Por último, fue a principios del siglo XXI cuando se publicó una investigación sobre la contrarreforma agraria de Pinochet, directamente informada por las fichas de expropiación de los archivos de la CORA, donde se pudo acompañar la trayectoria patrimonial específica de cada propiedad rural del país (Bellisario, 2007a, 2007b). Bellisario revisó seis mil expedientes de expropiación y los acuerdos del Consejo. Con las fichas, pudo superar datos agregados y sistematizar de manera más sofisticada los cinco procedimientos de la dictadura para descoyuntar el sector reformado: 1) revocación de la expropiación; 2) parcelación; 3) transferencias; 4) arremates y venta directa; y 5) reservas CORA. Las fuentes permitieron al autor proponer conceptos más especializados y reinterpretar el proceso.

Bellisario (2007a: 18) explica que cada procedimiento de reversión de la reforma agraria ocupó una temporalidad específica. Entre 1974 y 1975, por ejemplo, la dictadura se ocupó de devolver las tierras a los antiguos dueños. Revocó integralmente las expropiaciones de 1.736 fundos ( $26 \%$ de las tierras reformadas), acusadas como ilegalidades de Allende. Otras 2.176 propiedades fueron parcialmente devueltas ( $7 \%$ de la tierra expropiada), pues, según decían los militares, correspondían a derechos de reserva no respetados. En total, fueron 3.182.255 hectáreas devueltas, o sea, el 33\% del sector reformado, casi inmediatamente después del bombardeo al Palacio de La Moneda.

Entre 1976 y 1978, la CORA se concentró en los proyectos de parcelación. Las parcelas ocuparon, en principio, el $41 \%$ del sector reformado, vendidas a 54.564 familias campesinas; sin embargo, el $15 \%$ de ellas no eran productivamente viables ${ }^{15}$. La política de parcelación combinó tres situaciones: 1) unidades agrícolas familiares con $10 \mathrm{HRB}$ de media que ocuparon el $21 \%$ del sector reformado para 37.405 familias; 2) viviendas rurales con huerto de cien metros cuadrados, vendidas a 7.685 familias; y 3) predios de secano, sin vivienda y sin viabilidad productiva, vendidos a 2.114 familias en 132 unidades, equivalentes al 8\% del sector reformado (Bellisario, 2007a: 21). En el mismo periodo, las 191 cooperativas campesinas asignadas antes del golpe militar, es decir, el $11 \%$ del sector reformado con títulos estables, fueron compulsoriamente disueltas y parceladas. Entre las 9.669 familias cooperativistas, 2.839 fueron excluidas (Ibid.: 20). Además, el autor confirmaba que, en la liquidación del sector reformado, la dictadura no sólo vendió las parcelas, sino que cobró a los campesinos las deudas del sector reformado adquiridas en la unidad productiva, fabricando un doble endeudamiento.

15. Lo que explica la diferencia entre Cereceda y DAHSE (1980) y BENGOA (1983). 
Por fin, entre 1979 y 1980, durante el autonombrado proceso de normalización agraria, la CORA fue reemplazada por la ODENA (Oficina de Normalización Agraria), que arremató el $16 \%$ del sector reformado con fallos reminiscentes en tribunales y transfirió otro $9 \%$ a instituciones públicas, regalándolo a agentes militares.

Con base en los documentos, Bellisario argumentó que la mejor manera de conceptualizar tal proceso sería contrarreforma agraria parcial, una vez que la parcelación, por un lado, y la modernización agrícola empresarial, por otro, representaron la efectiva realización parcial del proyecto de reforma agraria. En otras palabras, la dictadura no operó una política de refundación del sistema de haciendas anterior a 1967, pues los militares fueron contrarios al retrasado sistema de latifundios. Querian otro sistema en su lugar, una agricultura modernizada, aunque dominada desde arriba por una burguesía agrícola (Ibid.: 27).

Con ese argumento, Bellisario consideró el término contrarreforma agraria impreciso. La solución militar al problema fue contradictoria, como fanus, el Dios romano, escribió. Por un lado, ellos dieron derechos de propiedad para una fracción significativa de familias campesinas de dentro y de fuera de la reforma agraria. [...] Por otro lado, restituyeron un tercio del sector reformado para los antiguos propietarios (Ibid.: 27). Sin desconsiderar la fundamental contribución del autor, es posible problematizar aspectos de su interpretación. Se puede cuestionar la aparente duplicidad que Bellisario encontró en las políticas agrarias de la dictadura, proponiendo, al contrario, una interpretación que enfatiza su coherencia e integralidad. Es decir, la represión contra los campesinos no fue una política aislada del proyecto económico agrario y las presiones especulativas contra las parcelas fueron multiplicadas por el contexto de intimidación. El terrorismo de Estado actuó en la estructura de propiedades en alianza con las presiones de mercado, como muestra la documentación analizada a continuación.

\section{LAS VIOLACIONES DE DERECHOS HUMANOS CAMPESINOS}

El informe de la Comisión Nacional de Verdad y Reconciliación de 1990, o informe Rettig (Gobierno de Chile, 1990), reconoció que, en los primeros tres meses y medio de dictadura (del 11/09/1973 al 31/12/1973), fueron ejecutados o desaparecieron 285 campesinos y 31 empleados de instituciones del agro a manos de agentes del Estado ${ }^{16}$. Las muertes y desapariciones campesinas de 1973 correspondieron al $85 \%$ del total regis-

16. El informe Rettig no ofrece agregados con los sectores analizados (datos contabilizados por la autora). 
trado (324), lo que demuestra la ferocidad y rapidez con que los militares atacaron el sector.

Fueron meses de terror. Entre el 5 y el 7 de octubre, 18 obreros agrícolas de los fundos El Morro, Carmen, Maitenes y Pemehue, fueron ejecutados cerca de Mulchén. Ninguno de ellos era militante político. A la Comisión se reportó que las víctimas fueron obligadas a golpearse entre sí antes del ametrallamiento. Durante la madrugada del 16 de octubre, fueron detenidos y desaparecieron 23 campesinos de tres asentamientos en Paine (Campo Lindo, 24 de Abril y Nuevo Sendero). En Valdivia, el 10 de octubre, fueron torturados y asesinados 17 obreros agrícolas del sindicato campesino Esperanza del Obrero, encontrados con cortes en las manos, en los dedos, en el estómago e incluso algunos se encontraban degollados y con sus testículos cercenados (Gobierno de Chile, 1990: 400). En el complejo maderero de Panguipulli ${ }^{17}$, fueron aproximadamente treinta los obreros agrícolas muertos o desaparecidos en aquellos meses. En la madrugada del 3 de octubre, 13 obreros agrícolas de Paine fueron detenidos por el Regimiento de Infantería de San Bernardo y sus cadáveres aparecieron en diciembre, en el patio 29 del Cementerio General. Fueron siete los campesinos mapuche secuestrados por la comisaría de Lautaro entre el 4 de octubre y el 8 de noviembre de la comunidad Manuel Levinao y los asentamientos Tres Luces y El Cardal. Los desaparecimientos y asesinatos de campesinos, individualmente o en grupos, fueron practicados en todo el territorio. El tratamiento de la Junta Militar a las familias de las víctimas se basó en mentiras, desprecio por la gente del campo y tortura sicológica. Usualmente, se les afirmaba que detenciones conocidas y con testigos nunca existieron, se les ocultaban las muertes o se les entregaba una urna sellada con prohibición de apertura y velorio (Gobierno de Chile, 1990).

Entre los campesinos asesinados y desaparecidos en esos meses, sólo el $21 \%$ pertenecían a partido político, mientras el 38\% participaba de organizaciones sociales (Gobierno de Chile, 1990). La violencia fue prominente en Bío Bío, Araucanía y Los Lagos: es el sector campesino el más afectado por los hechos violatorios de los derechos fundamentales de que este informe da cuenta (Ibid.: 394). Además, el efecto del terror e inseguridad se diseminaba: Si mataban al alcalde y a campesinos inocentes, ¿cómo saber quiénes serían los próximos?, alguien dijo a la Comisión (Ibíd.: 780). El miedo se instalaba en las comunidades rurales. En los años siguientes, entre 1974 y 1990, fueron reconocidos 39 campesinos asesinados y desaparecidos y 20 técnicos del agro. Entre ellos, el $20 \%$ militantes de partido y el $31 \%$ de organizaciones sociales.

17. Sobre la historia del complejo maderero de Panguipulli durante la Unidad Popular, véase RoBLES (2018). 
Las detenciones y torturas contra campesinos fueron, en muchas ocasiones, resultado de una alianza entre fuerzas policiales y propietarias. Los testigos escuchados en la Comisión Nacional sobre Prisión Política y Tortura (informeValech 1) (Gobierno de Chile, 2005) mencionaban detenciones con la participación de civiles organizados [...] especialmente en las zonas rurales (Gobierno de Chile, 2004: 418). Debido al enraizamiento histórico de la violencia en el medio rural, las detenciones y torturas en el campo pueden haber sido subestimadas. Lamentablemente, el informe Valech 1 no permitió identificar quiénes fueron los campesinos detenidos entre los 27.255 reconocidos en $2004^{18}$. Sin embargo, se puede mapear las cárceles donde hubo mayoría de detenidos campesinos.

En Coquimbo, por ejemplo, se registró que la mayoría de los detenidos eran campesinos en la cárcel de Ovalle, donde los presos políticos llegaban en condiciones deplorables por el maltrato que sufrían al momento de la detención (Gobierno de Chile, 2004: 347). Lo mismo en la comisaría de carabineros de Illapel. En O'Higgins, la comisaría de carabineros San Vicente de Tagua Tagua recibió mayor número de detenidos, que provenían de sectores agrícolas aledaños, como Zúñiga, Millahue, Requehua y de El Tambo (Ibíd.: 393). En la región de Maule, el Regimiento $\mathrm{n}^{\circ} 3$ de Curicó detuvo muchos dirigentes campesinos (Ibíd.: 402), como en la Escuela de Artillería de Linares y en la cárcel del Parral, donde los detenidos provenían en su mayoría de sectores campesinos (Ibíd.: 410). En Bío Bío, en la comisaría de carabineros $n .^{\circ} 3$ de Bulnes, gran parte [...] fueron campesinos detenidos durante operativos militares y de Carabineros en asentamientos y fundos (Ibíd.: 431). Igualmente, en la tenencia de carabineros de San Pedro de la Paz. En la Araucanía, un gran número de campesinos detenidos en sus hogares durante operativos conjuntos de carabineros y patrullas del Ejército (Ibid.: 461) fueron llevados a la tenencia de carabineros de Cunco, donde llegaban en muy malas condiciones fisicas (Ibíd.).

En Los Lagos, las detenciones se produjeron en los asentamientos campesinos y en el Complejo Maderero Panguipulli (Ibíd.: 478). Las víctimas llevadas a las comisarías de carabineros de Futrono, Panguipulli y Lago Ranco, donde permanecían en muy malas condiciones físicas, fueron desnudados, mojados y encerrados en calabozos muy húmedos. [...] Siempre incomunicados y muchos amarrados con alambre de púas (Ibid.: 479). En la Región Metropolitana, fue la subcomisaría de carabineros de Paine donde la mayoría de los detenidos eran campesinos de la zona, muchos de ellos dirigentes de asentamientos de la reforma agraria (Ibíd.: 519), como también en las tenencias de carabineros de Isla del

18. La clasificación adoptada por la Comisión diluyó la condición campesina en diferentes categorías, como trabajadores no calificados (5.681 detenidos), pequeños empresarios agrícolas (357 detenidos) o trabajadores calificados del agro (153 detenidos) (GoBIERNO DE CHILE, 2004: 563). Lo mismo en la Valech 2: trabajadores no calificados (1.596 detenidos), pequeños empresarios agrícolas (136 detenidos) o trabajadores calificados del agro (139 detenidos) (GOBIERNo DE CHILE, 2011:44). 
Maipo y Curacaví. Entre los lugares privados de detención, se destacó la bodega de vino Quebrada Honda, en Curacaví, donde casi la totalidad de detenidos [...] eran campesinos de la zona, trabajadores de asentamientos (Ibid.: 540). En el mismo sentido, hubo asesinatos dentro de propiedades particulares en el campo, como el caso de dos obreros agrícolas, dirigentes sindicales, encontrados muertos en la hacienda Las Canteras, en Bío Bío (Gobierno de Chile, 1990: 365).

En tales circunstancias, millares de campesinos fueron ayudados por los servicios del Departamento Campesino de la Vicaría de la Solidaridad. Creada en enero de 1976, en su primer año de labor, la Vicaría ya atendió a 1.631 juicios de campesinos que buscaron apoyo, incluidos 232 juicios laborales y 112 violaciones de derechos en el sector reformado. Sin embargo, en aquel año solo 30 sentencias les resultaron favorables ${ }^{19}$. El Departamento Campesino de laVicaría se proponía tres misiones: ofrecer asistencia jurídica a los campesinos expulsados de la tierra y despedidos del trabajo; asesorar la creación de empresas campesinas alternativas, formadas por los despedidos, ofertándoles crédito, asistencia técnica y productiva; y promover la capacitación. Su prioridad fue atender a todos aquellos a quienes se les aplicó el DL $208^{20}$.

El Departamento tenía oficinas en Santiago, Talagante, Melipilla y Buin, ocupadas por abogados. En las regiones, trabajaban con abogados asociados, contratados por temporadas y vinculados a organizaciones campesinas. Entre 1977 y 1982, los 31 abogados del Departamento Campesino entregaron 700 informes mensuales sobre los juicios. No obstante, la velocidad de la violencia, la amplitud de afectados y la distancia de las zonas rurales hacía muy difícil que los abogados de la Vicaría pudiesen apoyar a todos los necesitados. En 1980, por ejemplo, la Vicaría registró que el abogado encargado de apoyar la Unidad Obrero-Campesina en Linares fue amedrentado por el Intendente, y decide abandonar el programa (Ibid.: 12).

En la recepción del Departamento Campesino llegaron a ser atendidas 10.603 personas entre 1979 y 1981, lo que demuestra el desequilibrio entre la demanda campesina por ayuda y la cantidad de profesionales para acogerla en el contexto represivo ${ }^{21}$. Fueron asumidos no más de 2.098 conflictos judiciales, entre los cuales el $68 \%$ fueron la-

19. Fundación de Documentación y Archivo Vicaría de la Solidaridad, Arzobispado de Santiago de Chile (FDAVS), Memorias, doc. 0001700. Vicaría de la Solidaridad, "Ocho meses de labor», 1976.

20. FDAVS, doc. 0064200. Vicaría de la Solidaridad, Departamento Campesino, «Sistematización trabajo programa jurídico (octubre 1977-octubre 1982)", 1983b.

21. FDAVS, Memorias, doc. 0002700. Vicaría de la Solidaridad, "Quinto año de labor», 1980, p. 70. 
borales, el $22 \%$ civil-patrimoniales y el 10\% penales. Los tipos de conflicto campesino asistidos por la Vicaría están representados en el Gráfico 2.

\section{GRÁFICO 2}

\section{Conflictos atendidos por el Departamento Campesino de la Vicaría de la Solidaridad, 1977-1982}

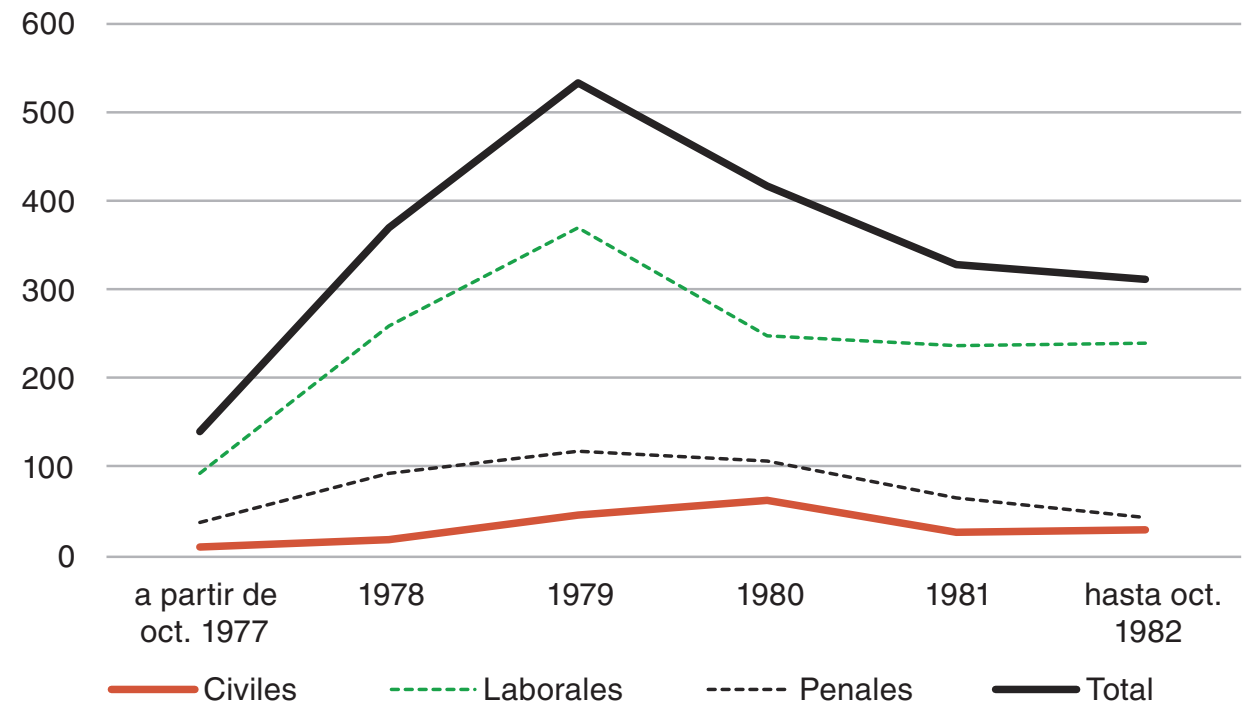

Fuente: elaboración propia a partir de FDAVS, doc. 0064200.Vicaría de la Solidaridad, Departamento Campesino, «Sistematización trabajo programa jurídico (octubre 1977-octubre 1982)», 1983b.

Entre los conflictos laborales, el $85 \%$ tenía su origen en despidos injustificados o incumplimiento de obligaciones patronales básicas (salarios, incentivos, seguridad social, regalías, feriados, descanso dominical, indemnizaciones, horas extras, faenas y otras remuneraciones debidas). Entre los conflictos civiles, el 23\% se originaba por indisposiciones con el término de una relación laboral de la cual dependía la vivienda y el huerto de subsistencia del trabajador, mientras las deudas campesinas representaban el $22 \%$ y las medierías, el $17 \%$. Los exbeneficiarios de la reforma agraria que protestaban contra su exclusión de las parcelas fueron un 13\%. Entre los tipos penales, un $45 \%$ fueron demandas contra delitos a la propiedad campesina (usurpación, robo, estafa); un 30\% fueron intentos de eliminar infracciones penales contra dirigentes campesinos de sindicatos o asentamientos; y un $25 \%$ representaban fallos por atentados a la vida de los campesinos ${ }^{22}$. La cuestión de la propiedad campesina, por lo tanto, protagonizaba los tres tipos de conflictos.

22. FDAVS, doc. 0064200. Vicaría de la Solidaridad, Departamento Campesino, «Sistematización trabajo programa jurídico (octubre 1977-octubre 1982)", 1983b. 
La exclusión del acceso a la tierra a los campesinos durante la dictadura fue inseparable de las violaciones de derechos humanos. En los informes de la Vicaría, se afirmaba:

Uno de los dirigentes sindicales entrevistados señalaba que Carabineros visita al trabajador despedido, a petición del empleador, y lo amenaza con desalojarlo violentamente, sin juicio alguno, si no hace abandono de la casa, en un plazo de días, que ellos fijan. El hecho que dicha amenaza normalmente se concrete, ha traído como consecuencia que el trabajador residente despedido no quiera exponerse a sufrir el desalojo violento, haciendo abandono de la habitación en el plazo que la fuerza pública le fija arbitrariamente (Ibid.: 165).

Es decir, junto con las ejecuciones, secuestros, torturas y detenciones, los agentes del Estado practicaban sistemáticamente actos de desarraigo contra los campesinos que nunca llegaron a ser oficialmente investigados. El Departamento Campesino los vivía cotidianamente. La Vicaría registraba que el periodo en que se produjo mayor violencia contra el campesinado fue anterior a su fundación (enero de 1976), de manera que sus registros y archivos no contemplaban una cantidad no mensurable de violaciones entre 1973 y 1975. El momento de mayores exclusiones sucedió inmediatamente después del golpe y se extendió hasta 1976 aproximadamente. Esto se produjo antes de que el programa pudiera registrarlos, alertaban. Muchas de estas exclusiones, en los momentos inmediatamente posteriores del golpe, no se ciñeron a regulación legal alguna, sino a los dictados de la fuerza de las armas, según recuerdan campesinos (Ibid.: 167). Los abogados reportaban que los campesinos fueron excluidos de la asignación individual de tierras, al momento de liquidarse las SARAs, pero no así de las deudas originadas en dichas liquidaciones (Ibid.: 166). O sea, estaban excluidos de la tierra, pero nunca de las deudas.

La angustia de los funcionarios de la Vicaría sugiere que su trabajo era duramente contrariado por el régimen. En más de cien juicios en que los campesinos fueron echados de su parcela de regalía por el patrón, perdiendo simultáneamente el trabajo, la vivienda y el huerto, los informes de la Vicaría admitían: No hay posibilidad de que un trabajador gane un conflicto de esta naturaleza. La estrategia usada por los abogados es demorarlo utilizando toda la batería de recursos que la ley otorga, para asi permitirle al afectado encontrar alguna solución al problema habitacional que se le presenta con el despido (Ibíd.: 139). Los abogados también denunciaron la arbitrariedad de la exclusión de campesinos por el decreto 208 frente a la ausencia de pruebas. La carencia de normas que regularan la prueba de la ocupación violenta, permitió a CORA excluir a campesinos de la asignación de tierras, con el solo informe de los antiguos dueños expropiados y de los servicios de seguridad (Ibíd.: 143). El profesor rural Rogelio Correa, que trabajó en la CORA con sistemas de puntaje en Linares durante la contrarreforma agraria, nos relató en una entrevista que muchos de los 
campesinos excluidos de la parcela por el 208 fueron trabajadores analfabetos que, frente a la orden de un militar, registraban su digital bajo la acusación de marxismo leninismo, sin tener claro lo que firmaban ${ }^{23}$.

La coerción militar y la persecución contra organizaciones campesinas afectaban la relación entre patrones y obreros agrícolas, generando pérdidas económicas irreparables. La Vicaría reportaba que los trabajadores no tienen suficiente poder de presión para exigir el pago completo de sus salarios, debido a la fuerte dependencia respecto a sus empleadores, la que no logra ser compensada, por las organizaciones sindicales y las inspecciones del trabajo, como sucedía antes del gobierno militar (Ibíd.: 89). Una abogada de Quilota contaba sobre el sentimiento de derrota moral que se desparramó en la clase campesina durante la dictadura: desde los sectores patronales se hace notorio un total desprecio al trabajador. [...] No ceden nada. El trabajador se siente disminuido frente a la prepotencia del empleador.Viene con ánimo derrotista, dispuesto a aceptar lo que se le dé. Se notan con temor frente a la autoridad del patrón, lo consideran imbatible (Ibíd.: 124). En Buín, otro abogado registraba la cohesión ideológica entre el patrón de fundo y la represión: la visión que el patrón tiene del trabajador que ahora reclama es la de un agitador comunista [...]. Los patrones amenazan a los trabajadores diciéndoles que le digan al sindicato que si van a sus fundos serán denunciados a los militares porque son unos comunistas, agitadores (Ibid.: 124). En síntesis, con base en el trabajo que hacía en las zonas rurales de todo el territorio chileno, la Vicaría registraba que, durante la dictadura:

\begin{abstract}
El problema laboral adquiere una dimensión politico-delictual, subvertidora del orden público [...]. Los sectores patronales sienten claramente la seguridad que les $\mathrm{da}$ la autoridad pública, a sus posiciones e intereses, lo que les ha permitido instaurar un verdadero «régimen de terror» entre los trabajadores agrícolas [...]. Fue un hecho reconocido por la gran mayoría de los abogados entrevistados, que un reclamo por prestaciones ordinarias expone al trabajador a una fuerte hostilización y a un posterior despido, en un corto plazo (Ibid.: 124, 129).
\end{abstract}

La represión laboral fue una continuación del terrorismo de Estado, estigmatizando a los campesinos que intentaban demandar mejorías a sus patrones, como terrenos para plantar su subsistencia. De acuerdo con la perspectiva de Barahona, que analizaba la pulsación del asedio interno y externo de las economías campesinas sobre las patronales ${ }^{24}$, la dictadura representó un momento en que la empresa patronal, aliada de la militariza-

23. Entrevista de Rogelio Correa a la autora. Santiago de Chile, 30/05/2019.

24. En los años 1960, Baraona coordinó un informe CIDA sobre Ecuador donde formuló tal perspectiva, adoptada por Bengoa. 
ción, anuló cualquier posibilidad de conquista territorial campesina en los nuevos sistemas de trabajo y condujo a un vasto proceso de desposesión. De esta manera la Vicaría comprendía el problema:

\begin{abstract}
Al substituir los pequeños propietarios tradicionales además de los parceleros individuales (provenientes de la reforma agraria) carentes de ayuda técnica y crediticia, este sector, que produce alimentos para el consumo interno con precios deteriorados, genera un patrón de acumulación que facilita la expansión del sector capitalista. [...] Se produce una gran reserva de trabajo subocupado, con la subsecuente presión por trabajo con menos salario, que es utilizado a requerimiento del sector empresarial en faenas temporales. La compraventa de parcelas (de los beneficiarios de la reforma agraria) se ha acrecentado, tornando la situación de los campesinos despojados en insostenible ${ }^{25}$.
\end{abstract}

Frente a tantos desafíos, la Unidad de Capacitación del Departamento Campesino ofreció cursos jurídico-sociales, formación sindical, juvenil, capacitación administrativa rural, jornadas sobre organización de unidades productivas, seminarios de dirigentes, entre otras. Entre 1976 y 1983, la Vicaría promovió 177 cursos y jornadas de capacitación campesina, con 4.564 participantes ${ }^{26}$. La Unidad de Capacitación generaba la posibilidad de crear una agenda propositiva al campesinado en un contexto defensivo. Según ellos, el programa de capacitación ha contribuido [...] al desarrollo y fortalecimiento de las organizaciones sindicales a través de los seminarios de capacitación jurídica, de análisis de la realidad agrícola y, sobre todo, a través del curso de formación técnico-sindical ${ }^{27}$. En el campo económico, en 1978, la Vicaría asistía a 72 familias beneficiadas por unidades productivas arrendadas por la Iglesia y a 90 familias con asesoría técnico-productiva. Planteaban articular la producción de estos campesinos con los programas asistenciales de alimentación para escuelas y poblaciones del Departamento de Zonas de la Vicaría ${ }^{28}$.

25. FDAVS, Memorias. Vicaría de la Solidaridad, «Sexto año de labor», 1981.

26. FDAVS, Memorias, doc. 5002500. Vicaría de la Solidaridad, «Un año de labor», 1977; Memorias, doc. 0002001. Vicaría de la Solidaridad, «Segundo año de labor», 1978; Memorias, doc. 0002500. Vicaría de la Solidaridad, «Tercer año de labor», 1979a; Memorias, doc. 0002608. Vicaría de la Solidaridad, "Cuarto año de labor», 1979b; Memorias, Vicaría de la Solidaridad, "Quinto año de labor», 1980; Memorias. Vicaría de la Solidaridad, "Sexto año de labor», 1981; Memorias. Vicaría de la Solidaridad, «Séptimo año de labor», 1982a; Memorias, doc. 0003200. Vicaría de la Solidaridad, "Octavo año de labor», 1983a.

27. Memorias, doc. 0002608. Vicaría de la Solidaridad, «Cuarto año de labor», 1979b, p. 70.

28. FDAVS, Memorias, doc. 0002001. Vicaría de la Solidaridad, «Segundo año de labor», 1978. 
En octubre de 1982, la Vicaría organizó el Simposio Nacional sobre Sindicalismo Campesino, con participación de 200 campesinos provenientes de Vallenar a Coyhaique. Se reunieron en Punta de Tralca con profesionales técnicos del agro de 21 instituciones de apoyo $^{29}$. Un poema que marcó el simposio retrataba el sufrimiento de las poblaciones rurales víctimas de la dictadura y el intento de creación de una narrativa de unidad sindical y esperanza en un futuro mejor, que sería conquistado a través de un nuevo ciclo de luchas ${ }^{30}$. Decía el poema:

La contrarreforma agraria

Nos causó grandes quebrantos

Emigraciones, por tanto

Y una enorme cesantía.

Pero la gran mayoría

Aún se encuentra en el campo.

[...] Como pedir no se puede

Al olmo que nos dé peras

Ni que flores, la higuera

O las parras den claveles,

Soldados ni coroneles

Hablarán nuestro lenguaje

$Y$ de capitán a paje

Cumplen la misma doctrina.

Legislación campesina

No es tela de ese ropaje.

[...] Hay miles de parceleros

Que casi ya no producen,

Pues la dispersión conduce

Tan sólo al despeñadero.

El dependiente, el mediero

$Y$ el mapuche están muy mal.

En la lucha sindical

Todos debemos unirnos.

29. FDAVS, Documento, doc. 2145a. Vicaría de la Solidaridad, «Acción Solidaria por la Justicia Social", ponencia en el Simposio Nacional sobre Sindicalismo Campesino, 1982b.

30. FDAVS, Documento, doc. 2145a. Vicaría de la Solidaridad, «Sindicato y Sociedad», ponencia en el Simposio Nacional sobre Sindicalismo Campesino, 1982c. 
Salir de este gran martirio

Es un común ideal.

Entonces el crecimiento

Del sindicato es posible.

La cuestión es imprimirle

Más confianza al movimiento.

[...] Volvemos a encontrarnos

Las esperanzas renacen

Puede ser que luego pasen

Estas penurias del agro.

Estos momentos amargos

Con su cola de secuelas

Cual cicatriz de viruela

Aunque duela, pasarán.

El humano en su crear

Sacará pan de la tierra.

[...] Es del máximo interés

$Y$ el futuro no me aterra

Que los que labran la tierra

Serán grandes otra vez.

Más allá de compartir sufrimientos, el poema revelaba un sentimiento político campesino. Cuando decían que la gran mayoría aún se encuentra en el campo, resistían contra la narrativa que identificaba el campesino como residuo del retraso a ser superado por la modernización. Según Ortega, el sector seguía con su agencia activa, debido a una característica fundamental de los hombres y mujeres rurales: la resiliencia campesina. Es decir, a pesar de la contrarreforma agraria y de la sistemática violación de derechos humanos (entre ellos, los de propiedad), en 1985 la empresa campesina representaba todavía el $25 \%$ de la producción de alimentos en Chile y el 35\% del valor de producción (Ortega, 1987: 178, 215). Aunque el $47 \%$ de su producción y el $68 \%$ de sus propietarios se encontrasen debajo del umbral crítico de pobreza y en privación extrema en fines de los años 1980, la productividad campesina era resiliente (Ibíd.: 179, 197). Observación similar hizo Kay (2002: 482-483) cuando señaló que en los años 1990 el sector campesino chileno todavía ocupaba el $39 \%$ de la tierra fértil, lo que representaba el $26 \%$ de la renta agrícola y el $36 \%$ de la fuerza laboral, mientras en las haciendas capitalistas, con el $61 \%$ de la tie- 
rra y el $74 \%$ de la renta agrícola, se empleaba al $48 \%$ de la fuerza laboral rural del país en modalidad temporera, personas que dependen -nuevamente- de la empresa campesina en la estación de desempleo. En este contexto ocurre la discusión sobre la reconversión campesina en los gobiernos de la Democracia Cristiana de los años 1990, quienes proponen, desde una perspectiva neoliberal, estrategias de crecimiento del ingreso campesino formuladas en términos de competitividad, y nunca de solidaridad comunitaria ${ }^{31}$.

\section{JUSTICIA DE TRANSICIÓN Y CUESTIÓN AGRARIA EN CHILE}

Antes de 1998, a excepción de la Comisión Rettig, fueron pocas las iniciativas gubernamentales para oficializar un sistema de justicia de transición amplio en Chile. Según Collins, existen dos miradas opuestas sobre el proceso de transición democrática en el país: la primera lo admira como ejemplo de las virtudes de la paciencia y el incrementalismo; mientras la segunda lo califica como un caso de excesiva cautela (Collins, 2013: 84). Hasta 1998, según la autora, las políticas de reparación se concentraron en dos modalidades: indemnizaciones a las familias de las víctimas individualizadas por el informe Rettig y programas especiales de acceso a la salud pública para los sobrevivientes. Fuera de eso, predominó lo que se llamó la postura del avestruz, con los gobiernos optando por huir de sus responsabilidades frente a las demandas de justicia, reparación, verdad y memoria. Según sistematizó Collins (2013: 92-95), durante el gobierno de Patricio Aylwin existieron cinco medidas reparatorias:

1. Oficina Nacional de Retorno (ley 18.994, 20/08/1990): apoyaba la reinserción de los exiliados que retornasen hasta el 31/12/1993.

2. Programa de Reparación y Atención Integral en Salud (PRAIS) (resolución exenta 729, 16/12/1992): atención a la salud física y psicológica para los familiares de las «víctimas Rettig» y para los defensores de derechos humanos que trabajaron con las víctimas.

3. Reparaciones económicas para los familiares de las «víctimas Rettig» (ley 19.123, 08/02/1992): pensiones, becas educacionales y exención del servicio militar obligatorio.

31. La discusión sobre la reconversión o transformación de padrones de producción en la agricultura refleja tal vez el más serio intento de los dirigentes políticos de gobiernos democráticos desde 1990 por configurar una politica agraria diferente [...], cuyos términos caminan junto con la continuidad fundamental de las políticas agrícolas neoliberales en los regímenes democráticos [...]. La reconversión no puede ser considerada como una panacea (KAY, 2002: 484, 492) (Traducción de la autora). 
4. Programa de exonerados políticos (Gobierno de Chile, 1993): proponía reponer años de cotización y otras protecciones sociales para personas despedidas del trabajo por razones políticas.

5. Memorial del Detenido Desaparecido y del Ejecutado Político: en 1994 fue construido un muro en el Cementerio General con los nombres de las víctimas.

Ninguna de estas medidas contemplaba los problemas específicos del campesinado. En la ley 19.234, que estableció las pensiones para exonerados políticos, no estaban presentes ni siquiera las palabras campesino, asentado, agrícola, tierra, rural o analfabeto. Aun así, los exasentados que postularon como exonerados llegaron a 7.685, pero apenas el 8\% fueron reconocidos, es decir, 634 campesinos (Bulnes et al., 2000: 66-67). El desequilibrio fue admitido por el gobierno de Eduardo Frei Ruiz Tagle cuando propuso la única mirada particular al sector campesino, en los casos tipificados como exonerados de tierra. La propuesta entregaba una pensión a quienes perdieron el derecho a parcela por el decreto 208. Más allá del hecho de que las pensiones monetarias son simbólicas, pues no reparan la pérdida de todo lo que significa ser dueño de la propia tierra y dejarla como herencia a los hijos, su alcance fue restricto. Hasta junio de 1996, el Estado otorgó 336 pensiones vitalicias a campesinos expulsados del sector reformado, con prioridad a los mayores de 65 años, equivalentes a menos del 7\% de las 5.000 víctimas del 208 (Lira \& Loveman, 2002: 132).

Finalmente, al llegar el gobierno de Ricardo Lagos, ocurrió un movimiento subterráneo en el sentido de una reparación campesina sustancial, que resultó en los informes encajonados. Considero importante narrar esa historia pues con ella se puede iluminar una intención gubernamental poco visible y, al mismo tiempo, comprender las potencialidades y límites de la conexión entre cuestión agraria y justicia de transición en Chile. Más que eso: el trabajo de escucha y entrevistas realizado por el equipo de los informes encajonados demuestra la potencialidad que pudiera tener una comisión de la verdad campesina, considerado el alejamiento que se produce entre las subjetividades urbanas y rurales en los espacios de justicia de transición de las ciudades. Los informes entregaron el cuerpo de recomendaciones para reparación campesina más desarrollado hasta hoy día, respaldado por estudios científicos, multidisciplinarios y de largo alcance.

En el 7 de marzo de 2000, el Ministerio de Agricultura firmó un convenio (decreto exento 39) con el Departamento de Derechos Humanos y Estudios Indígenas de la Universidad Arcis para la producción de un informe. El convenio solicitaba un estudio en dos etapas. La primera era la construcción de una muestra representativa, por regiones, de ca- 
sos concretos que presenten irregularidades en la situación de campesinos que perdieron sus tierras después del golpe del 11 de septiembre (Bulnes et al., 2000: 6). La segunda debería resultar en un análisis de la situación jurídica de los casos definidos, procediendo a proponer al Ministerio las alternativas para obtener la regularización de las tierras a favor de sus originales destinatarios o asignatarios, o a la reparación de los afectados (Ibid.: 10). El convenio se diferenciaba de las demás investigaciones sobre la contrarreforma por dos motivos: primero, surgió como determinación del Estado; y segundo, enunciaba objetivos de reparación histórica que, por primera vez, consideraban la posibilidad de una regularización de tierras.

Entre marzo y noviembre de ese mismo año, un grupo de cinco expertos en derechos humanos se dedicó a cumplir la solicitud. Estudiaron 690 casos de campesinos beneficiados por la reforma agraria que perdieron sus tierras en la dictadura en nueve regiones. Las sesiones de escucha fueron articuladas junto a la Confederación de Pequeños Agricultores y Pequeños Parceleros de Chile y otras organizaciones locales, como la Agrupación de Asentados y Ganaderos de la Hacienda Río Colorado ${ }^{32}$ (Ibid.: 6).

El resultado calificaba tres inflexiones antidemocráticas producidas en la política agraria después del golpe de 1973. La primera, el decreto 208. La segunda, la eliminación de la asistencia técnica, capacitación y crédito del Estado al campesinado. La tercera, la exclusión de los campesinos de la decisión y persecución de sus organizaciones (consejos, comités, sindicatos). En los casos investigados, el analfabetismo campesino fue clave en los procedimientos de estafa. El $47 \%$ de los campesinos entrevistados perdieron sus tierras por firmar contratos que no pudieron leer ni escuchar; el 39\% de ellos firmaron contratos de venta creyendo que fueran contratos de arriendo; el 10\% no recibió el pago completo por la venta de su parcela; y el $11 \%$ perdió la casa donde vivía con sus familias por largos años (Ibid.: 29).

Algunas historias destacan por su crueldad. En Linares, encontraron un campesino que, en pleno año 2000, trabajaba sin sueldo y a cambio de comida para el mismo hombre que le forzó a vender su parcela y su casa durante la dictadura (Ibid.: 31-32). En la Región Metropolitana, campesinos del proyecto de parcelación Manuel Larraín fueron obligados a firmar papeles en blanco, que posteriormente se transformaron en contratos de venta (Ibíd.: 35). En Molina, el jefe de área de la CORA confiscó la cosecha a los asentados sin pagarles,

32. La hacienda Río Colorado fue un asentamiento de 159.198 hectáreas formado en 1966 en San José del Maipo. En 1976, la dictadura transfirió sus tierras al Ejército. Los antiguos asentados y sus hijos, que trabajaron durante décadas para los militares, luchan por recuperar la propiedad de la tierra (URQuiETA \& SALÉm, 2018a, 2018b). 
amenazándoles con represión militar (Ibíd.: 36). Además, fueron encontrados casos emblemáticos de transferencia de tierras de reforma agraria para las Fuerzas Armadas, como el fundo San Antonio de Ancoa y la hacienda Río Colorado ${ }^{33}$. En el año 2000, los campesinos que vivían en esos fundos relataron tratamientos violentos, servidumbre y represión militar ocurridos en democracia. Junto al trabajo forzado, existieron indicios de venta irregular de parcelas por las Fuerzas Armadas (Ibid.: 50-55). La exclusión de la propiedad de la tierra, como muestra el caso de la hacienda Río Colorado, fue una violación del derecho intergeneracional, pues la tierra fue quitada también a los hijos que, excluidos con sus padres y madres, fueron sometidos a violaciones de tipo laboral después.

Considerando que esos campesinos no fueron asesorados jurídicamente por el Estado y que este cumplió un rol contrario al que le correspondía como garante de derechos, al actuar como agente de su violación, los autores del informe afirmaban: Lo que ocurrió con las parcelas asignadas no puede constituir una sorpresa para nadie, ni menos para quienes estuvieron detrás de las políticas agrarias del régimen militar. La intención básica fue que esas tierras quedaran entregadas al libre comercio (Ibid.: 38). Es decir, los informes demostraban que la represión política y las presiones económicas fueron causales sincronizados de la expulsión de los campesinos de la tierra que actuaban conjuntamente en la violación del derecho de propiedad. Como conclusión, sugirieron propuestas de reparación campesina, entre las que destacaba la necesidad de una investigación nacional más amplia:

1. Establecimiento de asistencia jurídica gratuita a los campesinos por medio de convenios del Estado con universidades.

2. Reconstrucción de programas de alfabetización y capacitación de trabajadores rurales.

3. Creación de cursos de ciudadanía sobre derechos y deberes, para prevenir la extorsión de las poblaciones campesinas.

4. Mayor fiscalización de los notarios, pues «dieron fe» sobre una masa de operaciones ilegales durante la dictadura y en democracia (Ibid.: 94).

5. Construcción de un catastro nacional de tierras con la trayectoria de desmantelamiento del sector reformado, el destino de las tierras y la situación del cam-

33. Sobre el primero, véase MARDONES (2017); sobre el segundo, URQUIETA y SALÉm (2018a, 2018b). 
pesinado a principio del siglo Xxi. Su finalidad sería viabilizar la realización de los procesos pendientes de la reforma agraria, respaldados por el artículo 2 de la ley 18.755 de $1989^{34}$.

El catastro nacional de tierras fue probablemente la única recomendación llevada adelante por el Gobierno, lo que condujo al segundo convenio. El 17 de noviembre de 2000, los resultados fueron presentados al ministro Jaime Campos Quiroga (Partido Radical), que los reconoció y los aprobó junto con la proposición de ampliar la metodología que los llevara a una política de reparación campesina integral, identificando a las familias que sufrieron violaciones del derecho de propiedad. En esta ocasión, la historia de los campesinos sometidos a trabajos agrícolas por las Fuerzas Armadas en el periodo democrático fue comunicada al Gobierno, en presencia de la entonces ministra de Defensa, Michele Bachelet ${ }^{35}$.

Fue firmado, entonces, el segundo convenio, que planteaba dimensionar el universo y situación de los campesinos que fueron destinatarios de la Reforma Agraria a fin de aproximar el número de los posibles beneficiarios de las medidas de reparación que en el estudio se proponen y el costo de su implementación (Bulnes, Fuenzalida \& Toledo, 2003: 193). El convenio señalaba que:

Continúa siendo hoy una importante preocupación del Ministerio procurar abrir caminos de solución a los campesinos que se encuentran en la situación descrita. [...] Es interés del Ministerio la celebración de un nuevo Convenio [...] para analizar la situación actual de las tierras provenientes del proceso de reforma agraria que conserva el Estado, y determinar la factibilidad de que éstas se apliquen efectivamente a los objetivos para los cuales fueron expropiadas (Ibid.: 194-195).

El segundo informe encajonado posee dos tomos. El primero está organizado en tres partes: la primera, un estudio de la legislación de la reforma agraria durante tres gobiernos (Alessandri, Frei Montalva y Allende), de las leyes agrarias de la dictadura ${ }^{36}$ y el re-

34. La ley establece que corresponderá al SAG ejecutar y celebrar todos los actos, contractos y actividades que sean necesarios para concluir los procesos de Reforma Agraria llevados a efecto en virtud de las leyes 15.020 y 16.640 (GobIERNO DE CHILE, 1989). Es contradictoria, pues simultáneamente deroga la ley 16.640 y cualquiera otra norma que permita expropiar predios con fines de reforma agraria (Ibid.).

35. Información oral transmitida por Sergio Fuenzalida el 17 de mayo de 2017.

36. Entre los decretos de la dictadura destacables por reinterpretar y alterar el sentido original de la reforma agraria están: el decreto-ley 208 (19/12/1973); el decreto-ley 1.600 (GoBIERNo DE CHILE, 1976); el decreto-ley 1.848 (GobIERNO DE CHILE, 1977); y el decreto-ley 2.221 (GobIERNo DE CHILE, 1978). 
ordenamiento jurídico del agro en democracia hasta 2003; la segunda, un análisis estructural de las propiedades rurales chilenas, basado en los expedientes de expropiación de la CORA (mismas fuentes de Bellisario, 2007). Aquí, entre las contribuciones novedosas están decenas de mapas de la contrarreforma, con la geografía de los cinco procedimientos: revocación, parcelación, transferencia, venta directa y reserva CORA (Bulnes, Fuenzalida \& Toledo, 2003: 98-105). En esta parte, el informe llegó al catastro de tierras, condensado en el Gráfico 3:

\section{GRÁFICO 3}

\section{Contrarreforma agraria en Chile, 1973-1990}

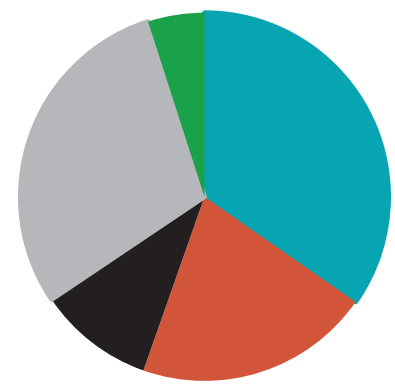

Restitución a antiguos dueños (35\%) - Transferencia a privados y Arremate (21\%)

- Transferencia a organismos públicos (10\%) Parcelación por endeudamiento (29\%)

$\square$ Saldo sin asignar (5\%)

Fuente: elaboración propia a partir de Bulnes, Fuenzalida y Toledo (2003: 121-122).

El informe también dimensionó la cantidad de campesinos destinatarios de la reforma agraria a los que se les impidió concretizar su derecho a la propiedad, por diferentes razones. Con el desglose de los proyectos de parcelación y análisis de las fichas de puntaje que seleccionaban a los campesinos, se concluyó que 50.277 campesinos fueron expulsados de la tierra durante la contrarreforma: 25.349 trabajadores de asentamientos con expropiación revocada, 5.000 campesinos eliminados por el decreto 208 y 19.928 campesinos que postularon a parcelas y fueron rechazados (Ibid.: 150). Además, muchos de los asentados postulantes a parcela, que originalmente tenían preferencia en el puntaje (decreto 435 de 1968), fueron desclasificados por la nueva legislación (decreto 165 de 1978) (Ibíd.: 180-185). Lo que no se logró actualizar en el informe fue la cantidad de parceleros que vendieron sus tierras entre 1990 y 2003, de modo que se admitió el estudio de Echeñique y Rolando (1991) como referencia. El informe entonces consolidaba el número de 70.277 familias campesinas excluidas del derecho de propiedad por la dictadura (Bulnes, Fuenzalida \& Toledo, 2003: 221-222). 
Por último, la tercera parte del informe trató de las responsabilidades jurídicas del Estado y de las recomendaciones reparatorias al campesinado. Con datos comprobatorios y vasta documentación, los autores concluyeron: resulta clarísimo que el Estado chileno violó abiertamente el principio de juridicidad, piedra angular del Estado de Derecho, y desconoció y atropelló derechos adquiridos de miles de campesinos. De ello debe nacer que él tiene de reparar el daño causado (Bulnes, Fuenzalida \& Toledo, 2003: 178). Eso porque cantidades de campesinos y sus familias terminaron quedando como víctimas de un proceso cuya finalidad y promesa era hacerlos dueños de la tierra (Ibid.: 188). Por lo tanto, la reconstrucción de la democracia, según escribieron:

\section{Obliga al Estado de Chile:}

1) En primer lugar, a no seguir postergando el cumplimiento de su deber jurídico con los campesinos que residen en las tierras que provienen del proceso de Reforma, y que el Estado aún conserva en su poder, en manos del SAG u otras instituciones;

2) A asumir una politica de reparación respecto de todos aquellos campesinos que habiendo reunido los requisitos suficientes para ser asignatarios de tierras no las recibieron por resoluciones antijurídicas de parte del Estado; $y$

3) Implementar también una política de reparación respecto de todos aquellos campesinos asignatarios de tierras, $y$ sus familias, que vieron frustrado sus expectativas de progreso social al haber tenido que venderlas al poco tiempo por falta del apoyo y auxilio, al levantarse las prohibiciones de enajenarlas (Ibid.: 188-189).

Por lo tanto, el Estado tendría que entregar las reservas CORA, todavía en poder del Fisco, del Ministerio de Bienes Nacionales, de las Fuerzas Armadas y la CONAF, a los destinatarios originales de la reforma agraria ${ }^{37}$, y garantizar una política de crédito y de proyecto productivo con apoyo del INDAP para asegurar la permanencia de las 70.277 familias campesinas excluidas del derecho de propiedad en la dictadura. Calcularon que un $25 \%$ de ellas (17.000) deberían ser contempladas con una inversión de 23.000 dólares, y alcanzar un monto total de 391 millones de dólares (Ibíd: 221-222). Por último, aclaraban: la indemnización, en este caso, asume una naturaleza «reparatoria» que debe concretarse en una voluntad de encontrar fórmulas que asuman y respondan a la realidad so-

37. Señalaron: esas tierras, en manos del SAG, o bajo la administración de otras instituciones del Estado, deben ser transferidas a los campesinos que las ocupan u ocuparon y que reúnan los requisitos que se establecieron para ser ellos sus asignatarios, de acuerdo a las normas que regulaban la asignación de tierras reformadas en las leyes y reglamentos respectivos (Bulnes, FuENZALIDA \& TOLEDO, 2003: 223). 
cial de los campesinos y las posibilidades para ellos más viables de adquisición y explotación productiva de la tierra (Ibíd.: 190). O sea, la tierra entendida como reparación.

\section{CONSIDERACIONES FINALES}

En 2004, los campesinos perseguidos por el decreto 208 fueron incorporados al acceso al sistema de salud pública vía PRAIS (Observatorio de Derechos Humanos, 2012: 8). Esa fue posiblemente la única medida de reparación campesina después de los informes encajonados. Al finalizar el estudio en 2003, el equipo de investigadores encontró obstáculos para difundirlos. No se conoce la cantidad de copias existentes, dónde podrían estar y tampoco las razones efectivas para su encajonamiento. Todo indica que el uso de las recomendaciones de los informes por las organizaciones campesinas fue escaso y el tema no mereció la consideración del Estado.

Como reflexión final, retomaré el argumento sobre la importancia de articular la cuestión agraria a la justicia de transición, con base en las evidencias documentales que vinculan la represión política contra los campesinos con el proyecto económico agrario de la dictadura en Chile. Como demuestran las fuentes, el poder militar de la dictadura afectó directamente la relación entre patrones y trabajadores del campo. Al mismo tiempo que la clase propietaria rural experimentó divergencias puntuales con la dictadura (Gómez, 1982), ocasionalmente perjudicadas por el neoliberalismo dogmático (Kay, 2002), de manera general, los patrones rurales encontraron en la represión militar un aliado para la explotación del trabajo. En este sentido, la violencia que afectó al sector campesino durante la dictadura afectaba múltiples dimensiones de sus vidas. Las ejecuciones, detenciones, desapariciones y torturas se coordinaban con la pérdida de la tierra (por el decreto 208, por el puntaje), el endeudamiento forzado, la estafa y venta forzosa de parcelas, el desarraigo y la explotación del trabajo. Los analfabetos, como siempre, eran más vulnerables.

Según Rojas, los sistemas de justicia de transición deben proveer reparación a las victimas de violaciones de los derechos humanos, incluyendo la reparación compensatoria, restitutoria, de rehabilitación y simbólica (Rojas, 2016: 132). La propuesta de un fondo de tierras para los excluidos por la dictadura, postulado por organizaciones campesinas en democracia y como repuesta por los informes encajonados, ocuparía la función de una reparación restitutoria. Además, otra dimensión de la justicia de transición es la garantía de no repetición. Si la represión política y el proyecto económico agrario forman parte de una agenda común de la dictadura, la no repetición implicaría mucho más que pensiones a los exonerados de tierra y atención a la salud de los afectados por el 208, sino la 
creación de un sistema económico de protección de los campesinos contra las presiones de concentración de la tierra.

El 17 de diciembre de 2018, la Declaración de las Naciones Unidas sobre los derechos campesinos y de otras personas que trabajan en las zonas rurales, afirmaba estar preocupada porque los campesinos y otras personas que trabajan en las zonas rurales sufren de manera desproporcionada pobreza, hambre y malnutrición [y] alarmada por el número cada vez mayor de campesinos y de otras personas que trabajan en las zonas rurales que son desalojados o desplazados por la fuerza cada año (ONU, 2018: 3). Además, señalaba que las personas, los grupos y las instituciones que promueven y protegen los derechos humanos de quienes se ocupan de cuestiones relacionadas con la tierra y los recursos naturales corren un gran riesgo de ser víctimas de diferentes formas de intimidación y de que se atente contra su integridad física (Ibid.: 4). Reconocía igualmente que los campesinos y otras personas que trabajan en las zonas rurales suelen tener dificultades para acceder a los tribunales, los agentes de policía, los fiscales y los abogados, hasta el punto de que no pueden obtener reparación ni protección inmediatas en caso de violencia, abuso y explotación (Ibid.: 4). Por fin, en su artículo 12, aseguraba: los campesinos y otras personas que trabajan en las zonas rurales tienen derecho a acceder de manera efectiva y no discriminatoria a la justicia, en particular a procedimientos imparciales de solución de controversias y a medidas de reparación efectivas por las vulneraciones de sus derechos humanos (Ibid.:10). Tales principios, si se materializaran en políticas, llevarían a soluciones de reparación campesina integral con derecho a propiedad de tierra.

En síntesis, en la medida en que los campesinos excluidos no lograron revertir tal proceso y que los objetivos originales de la ley de reforma agraria fueron reprimidos por medio de violaciones de los derechos humanos, es racional considerar que la contrarreforma agraria siguió vigente, en su expresión patrimonial (concentración de la tierra), laboral (relaciones de explotación), política (ausencia de la reforma agraria en el debate público) y subjetiva (silenciamiento campesino). Con este trabajo, buscamos identificar las conexiones inseparables entre el proyecto represivo y el proyecto económico agrario de la dictadura en Chile, para fortalecer la articulación entre la cuestión agraria y la justicia de transición. En fin, la verdadera reparación campesina, integral e intergeneracional, se materializaría en una nueva reforma agraria, lo que sigue en la mente de don Jacques Chonchol (2018).

\section{AGRADECIMIENTOS}

A los revisores de la revista de Historia Agraria, por los comentarios, sugerencias y correcciones. A FAPESP, por financiar la investigación. A Jacques Chonchol, Juan Vergara, 
Sergio Fuenzalida y Claudia Urquieta. A Domingo Gallego, comentador de mi ponencia en el II Congreso Internacional "Transiciones en la agricultura y la sociedad rural», en Santiago de Compostela, en junio de 2018.

\section{REFERENCIAS}

ACuÑa, L. (1986). Hombres y mujeres en Putaendo: Sus discursos y su visión de la historia. Santiago de Chile: CEM.

BARRAClough, S. \& FernándeZ, J. A. (1974). Diagnóstico de la reforma agraria chilena. México DF: Siglo XXI.

Bellisario, A. (2007a). The Chilean Agrarian Transformation: Agrarian Reform and Capitalist "Partial" Counter-Agrarian Reform, 1964-1980. 1: Reformism, Socialism and Free-Market Neoliberalism. Fournal of Agrarian Change, 7 (1), 1-34.

BellisARIo, A. (2007b). The Chilean Agrarian Transformation: Agrarian Reform and Capitalist "Partial" Counter-Agrarian Reform, 1964-1980. 2: CORA, post-1980. Fournal of Agrarian Change, 7 (2), 145-182.

BENGOA, J. (1983). El campesinado chileno después de la reforma agraria. Santiago de Chile: Ediciones Sur.

Bulnes, J. M., Celedón, R., Coll, M., FuenZalida, S. \& GonzÁlez, L. (2000). Identificación y diagnóstico jurídico de casos ilustrativos por regiones de tierras afectadas por la reforma agraria que presentan irregularidades en su adjudicación o tenencia actual, y alternativas de regularización, reparación o indemnización posible a sus beneficiarios originales, por vias administrativas, judiciales o legislativas. Santiago de Chile: Ministerio de Agricultura/Universidad Arcis.

Bulnes, J. M., FuenZalida, S. \& Toledo, V. (2003). Las tierras y los campesinos de la reforma agraria chilena: Leyes, asignatarios y destino: Informe Final. Convenio Ministerio de Agricultura/Universidad Arcis "Catastro Nacional de Tierras derivadas de la reforma agraria que no se adjudicaron a los beneficiarios de este proceso o que las perdieron y estudio de la situación socioeconómica de dichos originales beneficiarios». Santiago de Chile: Ministerio de Agricultura/Universidad Arcis.

Cereceda, L. \& Dahse, F. (1980). Dos décadas de cambios en el agro chileno. Santiago de Chile: Universidad Católica de Chile.

GobIerno De ChILE (1967a). Ley 16.625 de Sindicalización Campesina.

GobIERNo DE CHILE (1967b). Ley 16.640 de Reforma Agraria.

GobIERnO DE CHILE (1973). Decreto-Ley 208. Modifica la Ley 16.640 de Reforma Agraria y declara inexpropiables los predios que se encuentran en la situación que indica. Diario Oficial de la República de Chile, (28.730), 19/12/1973. 
GobieRno De ChiLe (1976). Decreto-Ley 1.600. Modifica la Ley 16.640 sobre reforma agraria y establece normas sobre enajenación de tierras asignadas. 17/11/1976.

GobieRno DE CHILE (1977). Decreto-Ley 1.848. Interpreta el inciso tercero de la Ley 16.640. 05/07/1977.

GobIERNo DE ChILE (1978). Decreto-Ley 2.221. Aclara alcances del artículo 67 de la Ley 16.640. 20/05/1978.

GOBIERNO DE CHILE (1989). Ley 18.755. Establece normas sobre el servicio agrícola y ganadero, deroga a la Ley 16.640. 07/01/1989.

GobIERNo DE CHILE (1990). Informe de la Comisión Nacional de Verdad y Reconciliación. Informe Rettig.

GobIERNo DE CHILE (1993). Ley 19.234. Establece beneficios provisionales por gracia para personas exoneradas por motivos políticos. 12/08/1993.

GOBIERNO DE CHILE (2004). Ley 19.992. Establece pensión de reparación y otorga otros beneficios a favor de las personas que indica. 24/12/2004.

Gobierno de Chile (2005). Informe de la Comisión Nacional sobre Prisión Política y Tortura. Informe Valech 1.

GobieRno De Chile (2011). Informe de la Comisión Presidencial Asesora para la Calificación de Detenidos Desaparecidos, Ejecutados Políticos y Víctimas de Prisión Política y Tortura. Informe Valech 2.

Chonchol, J. (2018). Por una nueva reforma agraria para Chile. Santiago de Chile: LOM.

Collins, C. (2013). Chile a más de dos décadas de justicia de transición. Revista de Ciencia Política, 51 (2), 79-113.

ECheÑIQue, J. \& Rolando, N. (1991). Tierras de parceleros: ¿Dónde están? Santiago de Chile: Agraria.

FuenZAlidA, S. \& Toledo, V. (2004). Actos del Estado y la reforma agraria chilena: Notas para un estudio histórico-jurídico. América Latina: Revista del Doctorado en el Estudio de las Sociedades Latinoamericanas, (4), 155-182.

GómEZ, S. (1982). Instituciones y procesos agrarios en Chile. Santiago de Chile: FLACSO. Gómez, S. (2002). Organización campesina en Chile: Reflexiones sobre su debilidad actual. Revista Austral de Ciencias Sociales, (6), 3-18.

GómeZ, S., ARTEAGA, J. M \& CRUZ, M. E. (1979). Reforma agraria y potenciales migrantes. Santiago de Chile: FLACSO. (Documento de Trabajo, 82).

GómeZ, S. \& ECHEÑIQUe, J. (1986). Trabajadores temporeros de la agricultura moderna del Chile Central. Santiago de Chile: FLACSO. (Documento de Trabajo, 324).

GómeZ, S. \& ECHEÑIQUe, J. (1987). La agricultura chilena: Las dos caras de la modernización. Santiago de Chile: FLACSO.

Harvey, D. (2004). O novo imperialismo. São Paulo: Loyola. 
JARVIS, L. S. (1985). Chilean Agriculture under Military Rule: From Reform to Reaction, 1973-1980. Berkeley: Institute of International Studies, University of California. (Research Series, 59).

KAY, C. (2002). Chile's Neoliberal Agrarian Transformation and the Peasantry. Fournal of Agrarian Change, (2) 4, 464-501.

Kay, C. \& Silva, P. (Eds.) (1992). Development and Social Change in the Chilean Countryside: From the pre-Land Reform Period to the Democratic Transition. Amsterdam: CEDLA.

LiRA, E. \& Loveman, B. (2002). El espejismo de la reconciliación política. Chile, 1990-2002. Santiago de Chile: LOM.

Loveman, B. (1976). Struggle in the Countryside: Political and Rural Labor in Chile, 19191973. Bloomington: Indiana University Press.

MARDONES, J. (2017). Los desconocidos negocios en los fundos del Ejército. The Clinic, Santiago de Chile, 04/07/2017.

Matheus, E. \& Silva, L. (2016). Desposeer para acumular: Reflexiones sobre las contradicciones del proceso de modernización neoliberal de la agricultura chilena. Mundo Agrario, 17 (34).

MeZarobba, G. (2007). O preço do esquecimento: As reparações pagas às vítimas do regime militar (uma comparação entre Brasil, Argentina e Chile). Tesis de doctorado. São Paulo: Universidade de São Paulo.

ObServatorio de Derechos Humanos (2012). Tabla leyes y medidas de reparación en Chile, 1991-2011. Santiago de Chile: Universidad Diego Portales.

ORganización de las Naciones Unidas (ONU) (2018). Declaración de las Naciones Unidas sobre los Derechos de los Campesinos y de Otras Personas que trabajan en las Zonas Rurales. Resolución n. ${ }^{\circ}$ AC373L30.

ORTEGA, E. (1987). Transformaciones agrarias y campesinado: De la participación a la exclusión. Santiago de Chile: CIEPLAN.

Rivera, R. \& CRUZ, M. E. (1984). Pobladores rurales: Cambios en el poblamiento y el empleo rural en Chile. Santiago de Chile: Academia de Humanismo Cristiano.

Robles, C. (2018). Revolution from below in Panguipulli: Agrarian Reform and Political Conflict under the Popular Unity in Chile. Fournal of Agrarian Change, 18 (3), 606631.

RojAs, C. (2016). La transición chilena y justicia transicional: Análisis crítico. Revista Derecho Eo Sociedad, (47), 129-144.

Silva, P. (1992). The State, Politics and Peasant Unions. In C. KAY \& P. Silva (Eds.) (1992). Development and Social Change in the Chilean Countryside: From the pre-Land Reform Period to the Democratic Transition (pp. 215-232). Amsterdam: CEDLA.

Toledo, V., FuenzalidA, S. \& Bulnes, J. M. (2004). Las tierras y los campesinos en la reforma agraria chilena: Responsabilidades y obligaciones pendientes del Estado. 
http://www.archivochile.com/Mov_sociales/mov_campe/MSmovcampe0006.pdf [Último acceso: $15 / 08 / 2017]$.

Tinsman, H. (2009). La tierra para el que la trabaja: Género, sexualidad y movimientos campesinos en la Reforma Agraria chilena. Santiago de Chile: LOM.

Tinsman, H. (2016). Se compraron el modelo: Consumo, uva y la dinámica transnacional: Estados Unidos y Chile durante la Guerra Fría. Santiago de Chile: Universidad Alberto Hurtado.

Urquieta, C. \& SAlÉm, J. (2018a). Historia de un despojo: Las tierras de la Reforma Agraria que el Ejército arrebató a campesinos. https://ciperchile.cl/2018/03/19/ historia-de-un-despojo-las-tierras-de-la-reforma-agraria-que-el-ejercito-arrebato-acampesinos/

URQuiETA, C. \& SALÉm, J. (2018b). Historia de un despojo II: Las tierras de la Reforma Agraria de las que no se habla. https://ciperchile.cl/2018/03/19/historia-de-un-despojolas-tierras-de-la-reforma-agraria-que-el-ejercito-arrebato-a-campesinos/.

VALDÉs, X. (1987). Sinopsis de una realidad ocultada: Las trabajadoras del campo. Santiago de Chile: Centro de Estudios de la Mujer.

VAldÉs, X., MACK, M. \& MATTA, P. (1986). Los trabajos de las mujeres entre el campo y la ciudad, 1920-1982. Santiago de Chile: Centro de Estudios de la Mujer.

VALDÉs, X. \& ARAUJO, K. (1999). Vida privada: Modernización agraria y modernidad. Santiago de Chile: Centro de Estudios para el Desarrollo de la Mujer. 